\title{
Determining Strain, Chemical Composition, and Thermal Properties of Si/SiGe Nanostructures via Raman Scattering Spectroscopy
}

\author{
L. Tsybeskov, ${ }^{a}$ S. A. Mala, ${ }^{a}$ X. Wang, ${ }^{a}$ J.-M. Baribeau, ${ }^{b}$ X. Wu, ${ }^{b}$ and D. J. Lockwood ${ }^{b}$ \\ ${ }^{a}$ Department of Electrical and Computer Engineering, New Jersey Institute of \\ Technology, Newark, NJ 07102, USA \\ ${ }^{\mathrm{b}}$ National Research Council, Ottawa, ON KIA 0R6, Canada
}

\begin{abstract}
Studies by Raman spectroscopy of two kinds of $\mathrm{Si} / \mathrm{SiGe}$ nanostructures-quantum dot multilayers and planar superlattices - reveal a wide variety of spectral features including first- and second-order Raman scattering, polarized Raman scattering, and low-frequency inelastic light scattering associated with folded acoustic phonons. Here we overview how such features can be employed to semi-quantitatively analyze the strain, chemical composition, and thermal conductivity in these industrially important materials that are widely used for producing electronic and optoelectronic devices.
\end{abstract}

\section{Introduction}

Inelastic light (Raman) scattering is an important general characterization technique (1), which, along with $\mathrm{x}$-ray diffraction $(2,3)$, can provide a great deal of information about the structural and, particularly for Raman scattering, the electronic properties of $\mathrm{Si} / \mathrm{SiGe}$ nanostructures (4-8). Raman scattering from semiconductor nanostructures involves a variety of different phonons that are observed according to strict optical polarization selection rules. Such scattering can also result in additional spectral features at wavenumbers between those of lower-frequency acoustic phonons and higher-frequency optical phonons (9). Similar to what is observed for bulk SiGe alloys, the Raman spectrum of $\mathrm{Si} / \mathrm{SiGe}$ nanostructures comprises three major bands with a $\mathrm{Si}$-like ( $\mathrm{Si}$-Si) peak at $\sim 500 \mathrm{~cm}^{-1}$, an alloy-like (Si-Ge) peak at $\sim 400 \mathrm{~cm}^{-1}$, a Ge-like (Ge-Ge) peak at $\sim$ $300 \mathrm{~cm}^{-1}$ together possibly with a crystalline $\mathrm{Si}(\mathrm{c}-\mathrm{Si})$ peak at $\sim 520 \mathrm{~cm}^{-1}$ depending on the sample composition, together with weaker Raman features located between the three major peaks $(4-8,10,11)$. These weaker Raman features are attributed to localized vibrational modes (e.g., Si-Si vibrations in the presence of a $\mathrm{Ge}$ atom, etc.) and various overtones $(9,12)$. Light scattering observed at low wavenumbers $\left(<100 \mathrm{~cm}^{-1}\right)$ is usually associated with various acoustic phonons, and second-order Raman scattering produces multiple overlapping peaks located between 600 and $1200 \mathrm{~cm}^{-1}$ (9). Thus, in Si/SiGe nanostructures the entire spectral region of $0-1200 \mathrm{~cm}^{-1}$ is covered by multiple Raman peaks, and the energies and appearances of these peaks display strong dependences on the growth conditions, strain, temperature and chemical composition.

The intensity of a Raman peak is proportional to its Raman cross-section and the scattering volume, which is related to the light penetration depth and hence the optical 
absorption coefficient (13). Resonant Raman scattering (RRS) occurs when the excited or scattered light approaches an energy gap in the material and is thus associated with significant changes in the Raman cross section, which are directly related to the joint density of states in the electronic bands of bulk materials or nanostructures (13). While c$\mathrm{Si}$ does not exhibit any resonances within the full visible spectrum, crystalline Ge (c-Ge) has a well-known resonance at $\sim 2.2 \mathrm{eV}$ associated with $\mathrm{E}_{1}$ and $\mathrm{E}_{1}+\Delta_{1}$ electronic transitions in the L direction of the Brillouin zone (9). Thus, in $\mathrm{Si} / \mathrm{SiGe}$ nanostructures the intensity of a Raman peak as a function of the incident light energy exhibits a broad peak around 2.2- $2.5 \mathrm{eV}(14,15)$. The optical polarization dependence of the Raman intensity of any given excitation is symmetry determined and is defined by its Raman scattering tensor (13). In $\mathrm{Si} / \mathrm{SiGe}$ nanostructures, an analysis of the polarization dependence of the light scattering has been used to detect various imperfections, including inhomogeneous strain, in epitaxially grown samples (16-18).

This overview of the use of Raman spectroscopy for characterizing $\mathrm{Si} / \mathrm{SiGe}$ nanostructures covers the following topics: what inelastic light scattering reveals in various such nanostructures with respect to both acoustic and optical phonons; analysis of strain and composition; evaluation of thermal properties; and the application of polarized Raman scattering in detecting strain.

\section{Introduction Growth and Structural Properties of Si/SiGe Nanostructures for both Superlattices and Cluster Multilayers}

Planar $\mathrm{Si} / \mathrm{Si}_{1-\mathrm{x}} \mathrm{Ge}_{\mathrm{x}}$ superlattices (SLs) are fashioned from alternating thin layers of $\mathrm{Si}$ and $\mathrm{Si}_{1-\mathrm{x}} \mathrm{Ge}_{\mathrm{x}}$ with $\mathrm{x}$ usually less than 0.5 and are commonly prepared by molecular beam epitaxy (MBE) growth on (001)-oriented Si substrates at a temperature of $\sim 500^{\circ} \mathrm{C}$ (see Fig. 1 and Ref. 19 for example). This relatively low growth temperature is chosen to produce dislocation-free pseudomorphic growth and to help prevent $\mathrm{Si} / \mathrm{SiGe}$ intermixing and thereby curtail the interface roughness. However, as can be seen from Fig. 1(b), the Ge composition in the alloy layer can vary across the start and end of the layer. For a SiGe layer with thickness below a critical value, the in-plane lattice mismatch between $\mathrm{Si}$ and $\mathrm{SiGe}$ is expected to be accommodated by a homogeneous tetragonal compression, which results in an extension of the lattice constant in the growth direction. These compressed SiGe layers are combined with the alternating Si layers, which may also be slightly strained, to form $\mathrm{Si} / \mathrm{Si}_{1-x} \mathrm{Ge}_{\mathrm{x}} / \mathrm{Si}$... strained-layered $\mathrm{SLs}$ that are usually capped with a Si layer.

Cluster multilayers $(\mathrm{CM})$ of $\mathrm{Si} / \mathrm{Si}_{1-\mathrm{x}} \mathrm{Ge}_{\mathrm{x}}$ are grown using $\mathrm{Si}_{1-\mathrm{x}} \mathrm{Ge}_{\mathrm{x}}$ layer thicknesses approaching, or above, the critical value, and hence the epitaxial growth of $\mathrm{SiGe}$ on $\mathrm{Si}$ requires relief of the elastic energy in the strained SiGe film (20-23). At high growth temperatures, the adatom diffusion and elastic deformation trigger a transition from twodimensional (2D) to three-dimensional (3D) growth modes. This 3D growth mechanism is known as Stranski-Krastanov (S-K) growth, and it is typically observed at MBE growth temperatures of $550-650^{\circ} \mathrm{C}$. As can be seen in Fig. 2(a), the strain involved during growth of the first two or three alloy layers produce self-organized dome-like structures (23) that stack up nicely throughout the remaining layers (see Fig. 2(b) and (c)). In the case of chemical-vapor-deposition based S-K growth, $\mathrm{GeH}_{4}$ diluted in $\mathrm{H}_{2}$ is used for providing the Ge atoms and spontaneous Si-Ge intermixing occurs due to thermal and strain-induced diffusion. In the S-K growth mode, most of the SiGe clusters (or islands) 
have a pyramid/dome-like (uncapped) or pancake-like (Si capped) shapes with the Ge concentration gradually increasing toward the cluster core (20-23).

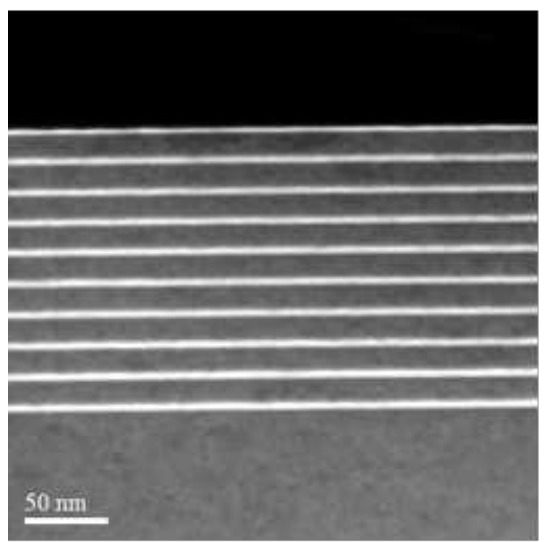

(a)

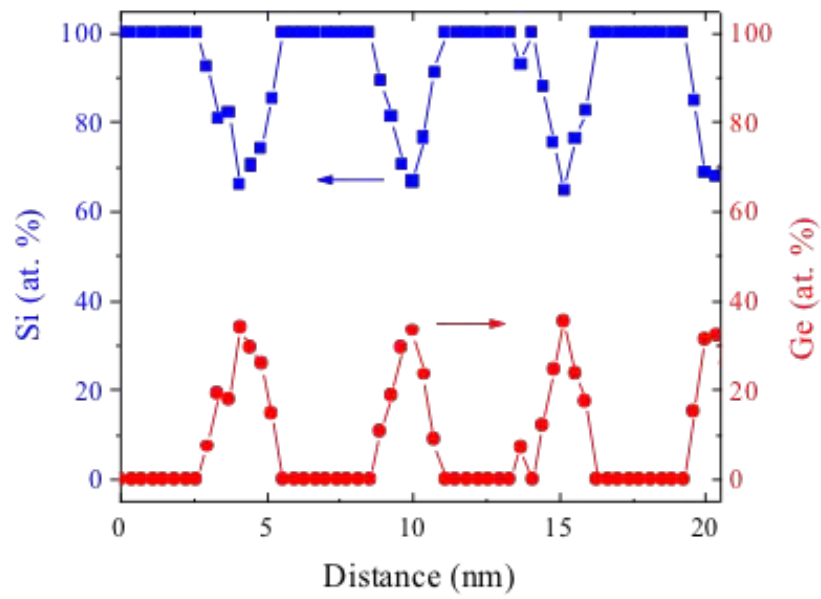

(b)

Figure 1. (a) Cross-sectional transmission electron micrograph (TEM) image of a $500^{\circ} \mathrm{C}$ MBE grown planar $\mathrm{Si} / \mathrm{Si}_{0.65} \mathrm{Ge}_{0.35}$ superlattice and (b) an energy dispersive X-ray (EDX) scan of the structure revealing the atomic composition of the top-most layers.

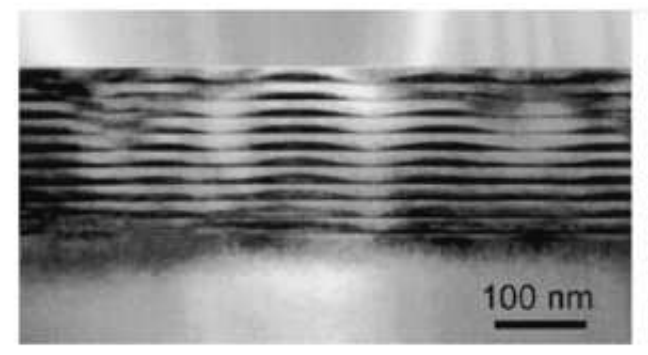

(a)

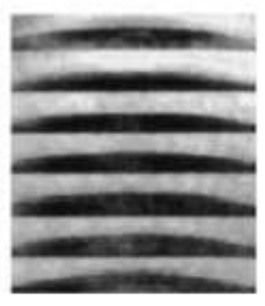

(b)

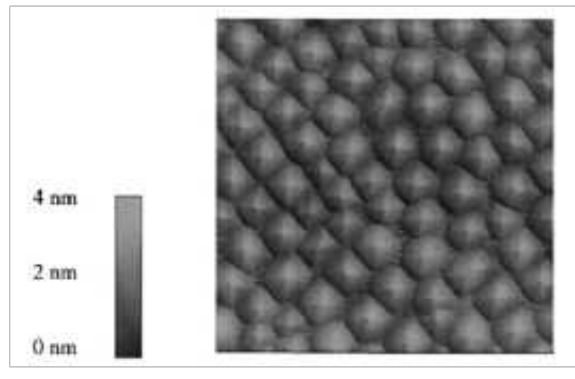

(c)

Figure 2. (a) Cross-sectional TEM image of a $650^{\circ} \mathrm{C} \mathrm{MBE}$ grown $\mathrm{Si} / \mathrm{SiGe}$ cluster multilayer nanostructure, (b) an enlarged TEM image of a section of the structure showing the strain-driven stacked growth of the SiGe clusters, and (c) an atomic force microscopy image of the uncapped alloy sample surface. 


\section{First-Order and Low-Wavenumber Raman Scattering in Si/SiGe Nanostructures}

The Raman spectrum of bulk $\mathrm{Si}$, as shown in Fig. 3, is comprised of a strong firstorder peak at $520 \mathrm{~cm}^{-1}$ that is surrounded by a variety of weaker second-order features that are associated with various combinations of acoustic and optical phonons. A SiGe alloy Raman spectrum is even more complicated, as can be seen in Figs. 4 and 5. Here, in accordance with the expectations mentioned above, three first-order Raman lines are visible. These three lines are usually weaker and wider than that of c-Si and can be asymmetric in shape. Also, the underlying continuum of second-order scattering is modified from that found in Si and is relatively stronger. Such differences need to be kept in mind when interpreting Raman spectra of $\mathrm{Si} / \mathrm{SiGe}$ nanostructures.

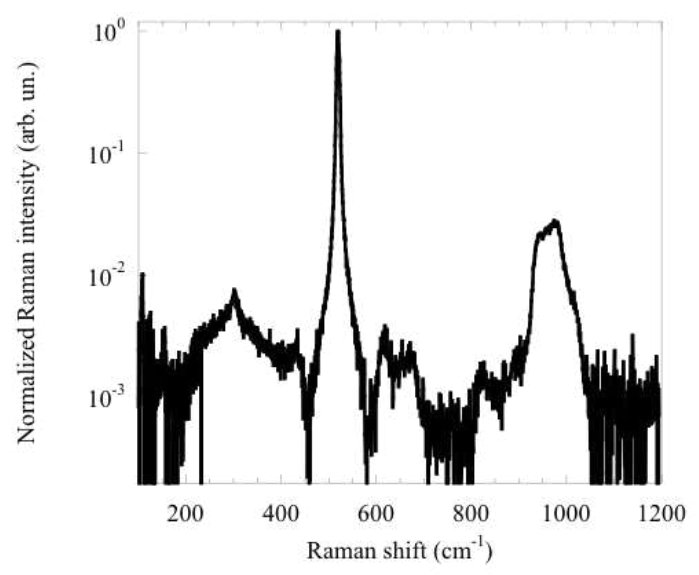

Figure 3. Raman vibrational spectrum of bulk c-Si at room temperature showing a very strong and sharp peak at $520 \mathrm{~cm}^{-1}$ that arises from first-order Raman scattering and various other weaker and broader features arising from second-order scattering. Note the use of a logarithmic vertical scale.

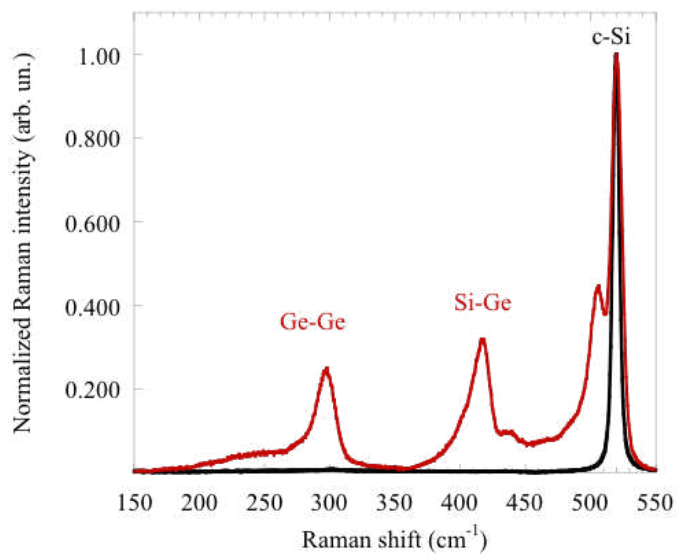

Figure 4. Room-temperature Raman spectrum of a $\mathrm{Si} / \mathrm{Si}_{1-\mathrm{x}} \mathrm{Ge}_{\mathrm{x}} \mathrm{Si} / \mathrm{SiGe}$ cluster multilayer nanostructure showing major peaks associated with the Si layers at $520 \mathrm{~cm}^{-1}$, and the strained alloy layers due to Si-Si (at $\sim 500 \mathrm{~cm}^{-1}$ ), Si-Ge (at $\sim 400 \mathrm{~cm}^{-1}$ ), and Ge-Ge (at $\sim 300 \mathrm{~cm}^{-1}$ ) type lattice modes. A normalized Raman spectrum of $\mathrm{c}-\mathrm{Si}$ is shown for comparison. 


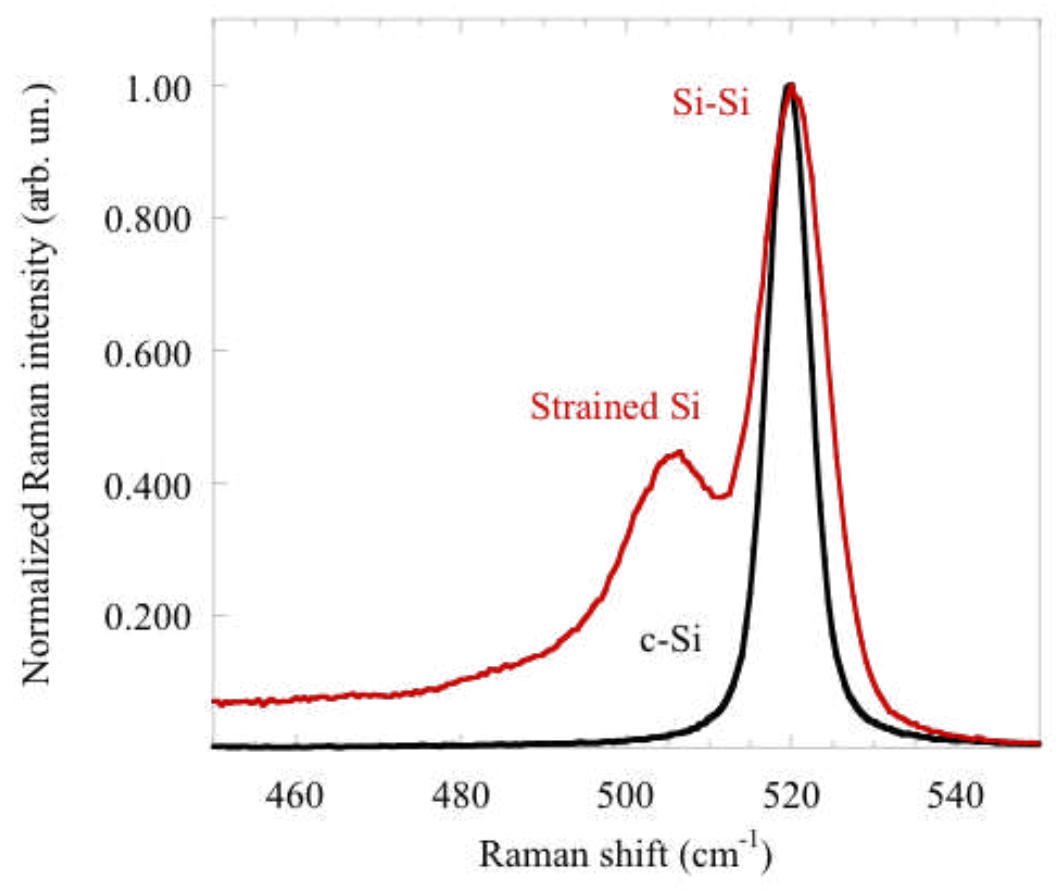

Figure 5. As for Figure 4, but showing only the Si-type vibrational modes of the Si and SiGe layers.

Figure 6 displays the Raman spectrum of a Si/Si ${ }_{1-x} \mathrm{Ge}_{x} \mathrm{SL}$ (see TEM image in Fig. 1) with the three distinct Raman peaks associated with the Si-Si, Si-Ge and Ge-Ge local bond vibrations. In addition to the major Si-Si Raman peak at $520 \mathrm{~cm}^{-1}$ with a full-width at half-maximum (FWHM) of 5-6 cm-1, a weaker peak at $505-506 \mathrm{~cm}^{-1}$ is found that is attributed to a $\mathrm{Si}-\mathrm{Si}$ vibration in the presence of a nearby $\mathrm{Ge}$ atom $(8,12,19)$. In both $\mathrm{Si} / \mathrm{SiGe} \mathrm{SLs}$ and S-K CMs, curve fitting of the spectra indicates that the FWHM of the $505-506 \mathrm{~cm}^{-1}$ peak precisely correlates with the FWHM of the major Raman peak at 520 $\mathrm{cm}^{-1}$ (12). It was concluded that in both $\mathrm{Si} / \mathrm{SiGe} \mathrm{SLs}$ and $\mathrm{S}-\mathrm{K} \mathrm{CMs}$, the Si layers separating the $\mathrm{SiGe}$ layers are strained and the strain in $\mathrm{SL} \mathrm{Si}$ layers is more homogeneous compared to that found in $\mathrm{CMs}$ (12). $\mathrm{Si} / \mathrm{Si}_{1-\mathrm{x}} \mathrm{Ge}_{\mathrm{x}}$ nanostructures with $\mathrm{x} \geq$ 0.4 and thicker SiGe layers usually show a main Si-Si type Raman peak at $\sim 490 \mathrm{~cm}^{-1}$ (Fig. 7) plus a weaker one at $510 \mathrm{~cm}^{-1}$, which is attributed to a localized Si-Si vibration mode arising from the presence of Ge (10). However, if the excitation wavelength is long enough so that the exciting light can reach the c-Si substrate, Raman peaks at 520, 508 and $490 \mathrm{~cm}^{-1}$ can all be observed (Fig. 7). Raman spectra associated with Si-Ge and GeGe vibrations in the SL sample are peaked at $417-418 \mathrm{~cm}^{-1}$ and $298-299 \mathrm{~cm}^{-1}$, respectively (Fig. 8). 


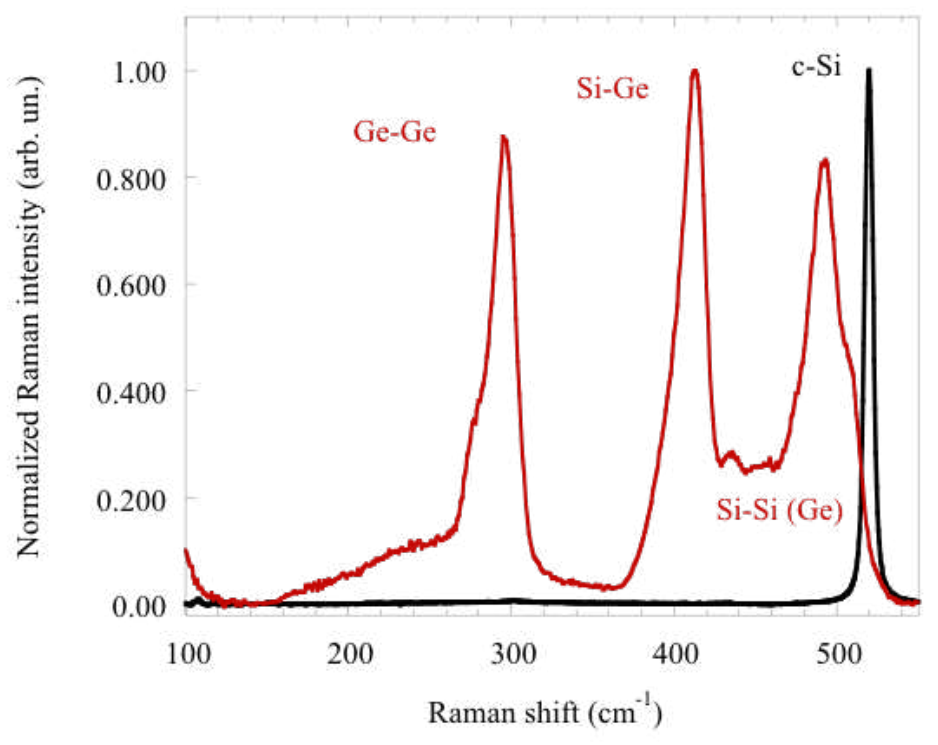

Figure 6. Raman spectrum at room temperature of a $\mathrm{Si} / \mathrm{Si}_{1-\mathrm{x}} \mathrm{Ge}_{\mathrm{x}}$ cluster multilayer nanostructure similar to the one shown in Fig. 2, with $\mathrm{x} \approx 0.5$, displaying peaks associated with first-order Brillion-zone-center optical phonons in the Si and strained alloy ( $\mathrm{Si}-\mathrm{Si}$, Si-Ge, and Ge-Ge modes). Notably, a peak due to the influence of a $\mathrm{Ge}$ atom on the $\mathrm{Si}-\mathrm{Si}$ mode $[\mathrm{Si}-\mathrm{Si}(\mathrm{Ge})]$ is also visible. The Raman spectrum was recorded with $457.9 \mathrm{~nm}$ excitation. The Raman spectrum of c-Si is given for comparison purposes.

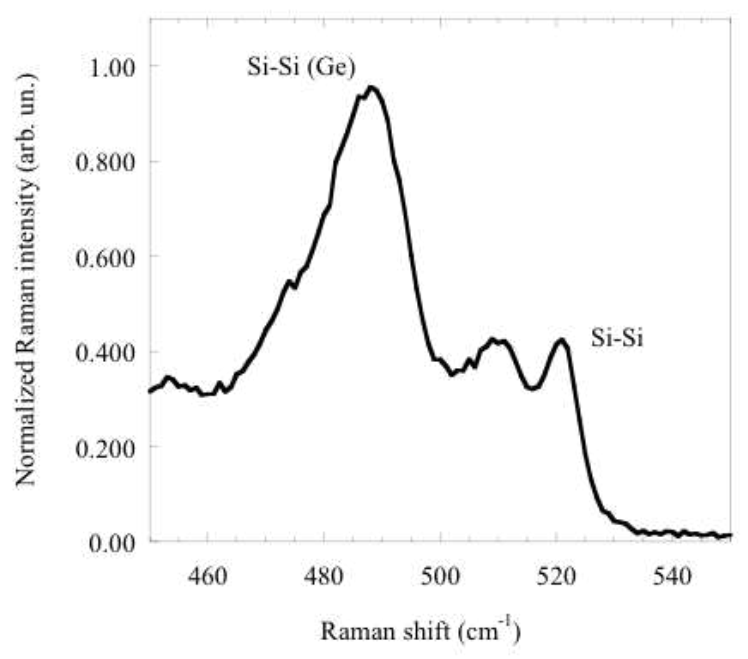

Figure 7. Room-temperature Raman spectrum of a $\mathrm{Si} / \mathrm{Si}_{1-\mathrm{x}} \mathrm{Ge}_{\mathrm{x}}$ cluster multilayer nanostructure with $\mathrm{x} \approx 0.5$ exhibiting a Raman peak at $\sim 490 \mathrm{~cm}^{-1}$ that is attributed to the local $\mathrm{Si}-\mathrm{Si}$ vibration mode in the presence of $\mathrm{Ge}[\mathrm{Si}-\mathrm{Si}(\mathrm{Ge})]$. Raman peaks are also observed at $508(\mathrm{Si}-\mathrm{Si})$ and $520(\mathrm{c}-\mathrm{Si}) \mathrm{cm}^{-1}$. The Raman spectrum was recorded with $514.5 \mathrm{~nm}$ excitation. 


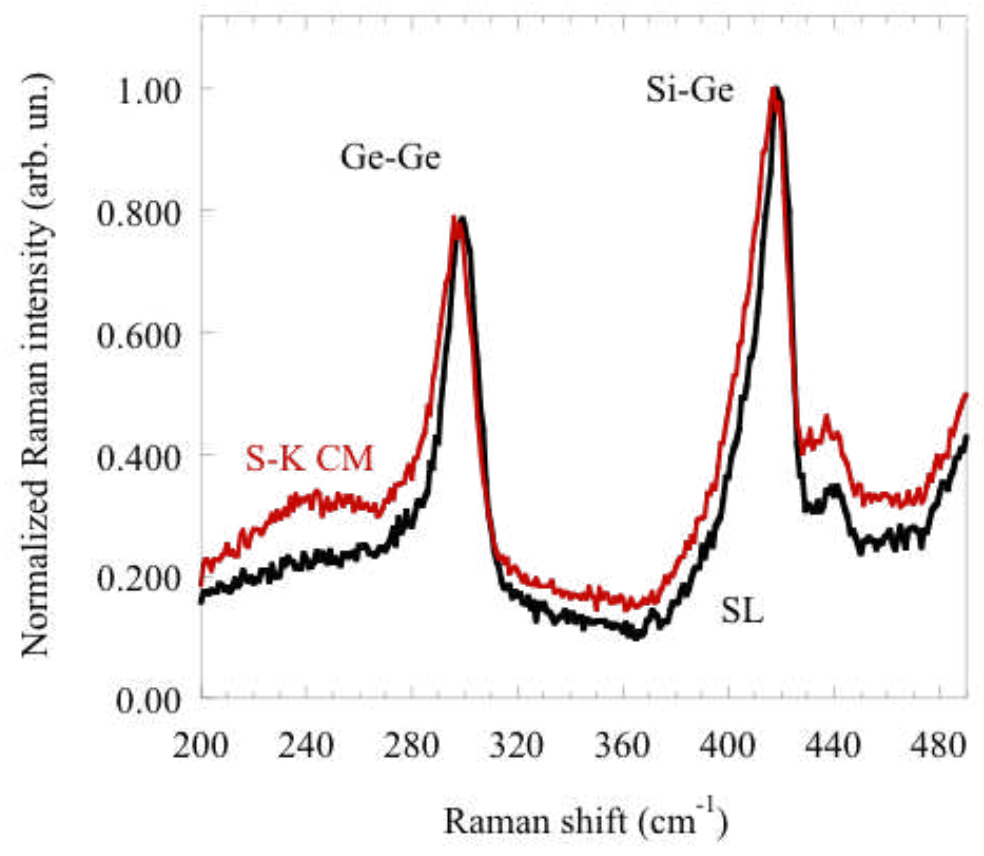

Figure 8. Room-temperature Raman spectra associated with Si-Ge and Ge-Ge vibrations at $417-418 \mathrm{~cm}^{-1}$ and $298-299 \mathrm{~cm}^{-1}$, respectively, in Si/SiGe Stranski-Krastanov cluster multilayers (S-K CM) and planar superlattices (SL).

In $\mathrm{S}-\mathrm{K} \mathrm{CM}$ samples, the $\mathrm{Si}-\mathrm{Ge}$ and Ge-Ge peaks are broader by $\sim 3 \mathrm{~cm}^{-1}$ and are slightly shifted toward lower wavenumbers compared to that in comparable SL samples, as shown in Fig. 8. In addition, the Raman spectra show weaker and broader peaks at $\sim 250 \mathrm{~cm}^{-1}$ attributed to the resonant Ge vibrational mode in the alloy and at $438 \mathrm{~cm}^{-1}$ associated with the local $\mathrm{Si}$ vibrational mode in the presence of $\mathrm{Si}$ and $\mathrm{Ge}$, respectively $(3,24)$. These peaks are enhanced in S-K CMs compared to SL samples, most likely due to the higher Ge composition. Figure 9(a) presents a summary of the reported dependence of the Raman peak wavenumbers associated with $\mathrm{Si}-\mathrm{Si}$, Si-Ge and $\mathrm{Ge}-\mathrm{Ge}$ vibrations on the composition $\mathrm{x}$ in bulk $\mathrm{Si}_{1-\mathrm{x}} \mathrm{Ge}_{\mathrm{x}}$ alloys, where there should be no strain (24). The results are compared to that in $\mathrm{Si} / \mathrm{SiGe}$ nanostructures with various degree of strain (Fig. 9(b)), and the following composition dependencies are found (24):

(a) In bulk $\mathrm{Si}_{1-\mathrm{x}} \mathrm{Ge}_{\mathrm{x}}$ alloys, the $\mathrm{Si}-\mathrm{Si}$ Raman peak wavenumber linearly decreases with increasing $\mathrm{x}$, as $\omega_{S i-S i}=521.2-67.91 x$. In $\mathrm{Si} / \mathrm{Si}_{1-\mathrm{x}} \mathrm{Ge}_{\mathrm{x}} \mathrm{SL}$ nanostructures, the dependence is much weaker; $\omega_{S i-S i}=519.9-29.82 x$.

(b) In bulk $\mathrm{Si}_{1-\mathrm{x}} \mathrm{Ge}_{\mathrm{x}}$ alloys, the $\mathrm{Ge}-\mathrm{Ge}$ Raman peak wavenumber linearly increases with increasing $\mathrm{x}, \omega_{G e-G e}=280.8+19.37 x$. In $\mathrm{Si} / \mathrm{Si}_{1-\mathrm{x}} \mathrm{Ge}_{\mathrm{x}} \mathrm{SL}$ nanostructures, the dependence is stronger; $\omega_{G e-G e}=282.0+33.53 x$.

(c) In bulk $\mathrm{Si}_{1-\mathrm{x}} \mathrm{Ge}_{\mathrm{x}}$ alloys, the $\mathrm{Si}-\mathrm{Ge}$ Raman peak wavenumber increases for $\mathrm{x}<0.6$ and decreases for $\mathrm{x}>0.6$ : $\omega_{S i-G e}=400.0+22.07 x-36.14 x^{2}+83.73 x^{3}-88.54 x^{4}$. However, in $\mathrm{Si} / \mathrm{Si}_{1-\mathrm{x}} \mathrm{Ge}_{\mathrm{x}} \mathrm{SL}$ nanostructures the dependence can be described as $\omega_{S i-G e}=$ $399.6+50.26 x-24.90 x^{2}$. 


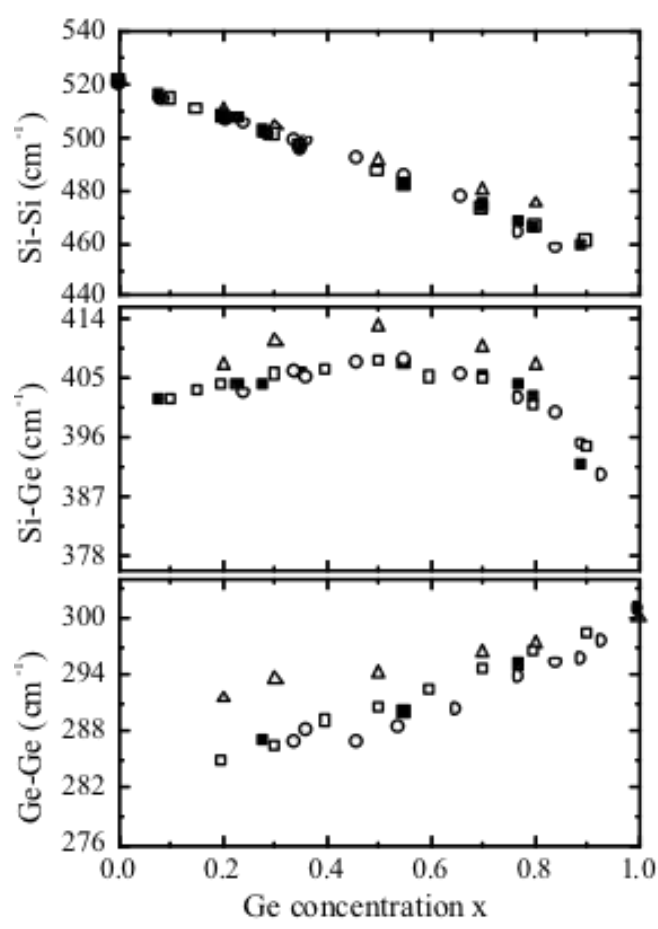

(a)

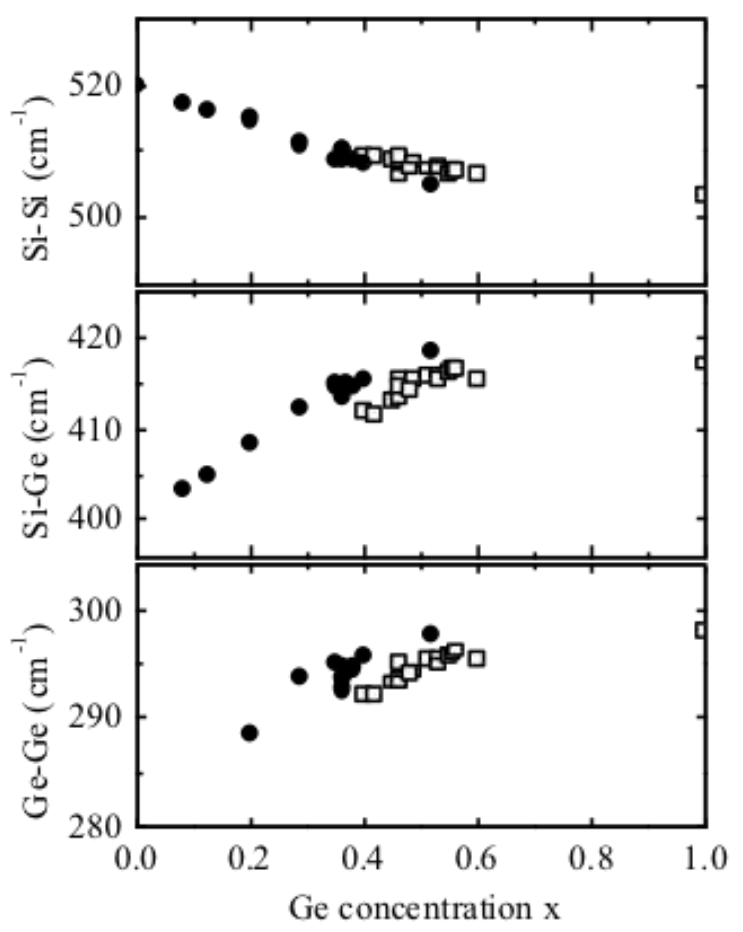

(b)

Figure 9. A summary of previously reported dependencies of the Raman peak wavenumbers associated with $\mathrm{Si}-\mathrm{Si}, \mathrm{Si}-\mathrm{Ge}$ and $\mathrm{Ge}-\mathrm{Ge}$ vibrations on the alloy

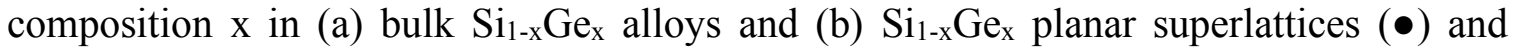
cluster multilayers $(\square)$ with various degrees of strain. See Reference 24 for further details.

The results presented here indicate that apart from just the average composition $\mathrm{x}$ of $\mathrm{Si} / \mathrm{Si}_{1-\mathrm{x}} \mathrm{Ge}_{\mathrm{x}}$ nanostructures other factors such as layer thicknesses, Si-Ge inter-diffusion, SiGe island sizes and shapes, and local strain should all be to be taken into account in analyzing the Ge concentration dependencies of the Raman peak wavenumbers and intensities. The most common explanation for the observed behavior is that an accumulation of $\mathrm{Ge}$ in the middle of planar layers and within the SiGe island core is responsible for a non-uniform composition and strain distribution (23). Possible detailed mechanisms include: the out diffusion of Ge and formation of compressed Si rich alloy regions in the valleys of the $\mathrm{Si}_{1-\mathrm{x}} \mathrm{Ge}_{\mathrm{x}}$ island multilayers; a strong diffusion coefficient dependence on the local Ge concentration in the film; and the tensile strain in the Si spacer layer placed on top of the SiGe islands $(3,24)$.

In $\mathrm{Si} / \mathrm{SiGe}$ periodic nanostructures, multiple Raman peaks at low wavenumbers $(<$ $100 \mathrm{~cm}^{-1}$ ) observed in the backscattering geometry are associated with folding of longitudinal acoustic (FLA) phonons due to the growth introduced new periodicity $P_{S L}$ and the formation of the Brillouin mini-zone. A commonly used method for the calculation of phonon dispersion curves is to use the elastic continuum model by Rytov (25). A condition of this model is that the wavelength of the sound wave should be much larger than the layer thickness. The elastic continuum approximation is then valid and the wave equation in each layer can be solved. Figure 10(a) shows the low-frequency Raman spectrum in a $\mathrm{Si} / \mathrm{SiGe} \mathrm{SL}$ (as shown in Fig. 1(a)) with distinct Raman doublets 
corresponding to various FLA modes. The inset shows a simplified FLA phonon dispersion diagram based on Rytov's model. In reality, band gaps appear at the mini-zone center and boundary (Fig. 10(b)) due to the difference in the acoustic impedances of the two component layers of the SL (19). These gaps are barriers to phonon propagation along the SL growth direction for those phonons having the appropriate energies and wave vectors. Thus, these $\mathrm{Si} / \mathrm{SiGe}$ periodic nanostructures are the first known examples of one-dimensional phononic crystals (19).

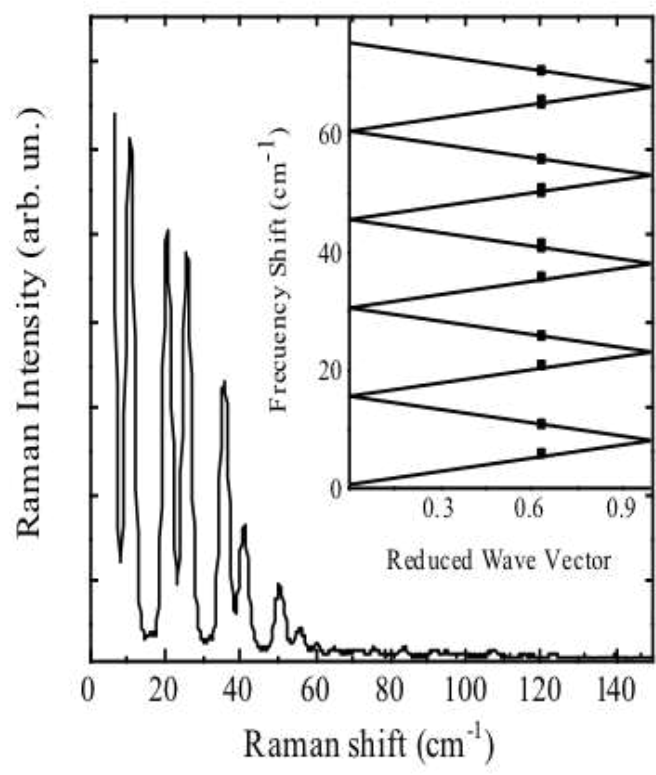

(a)

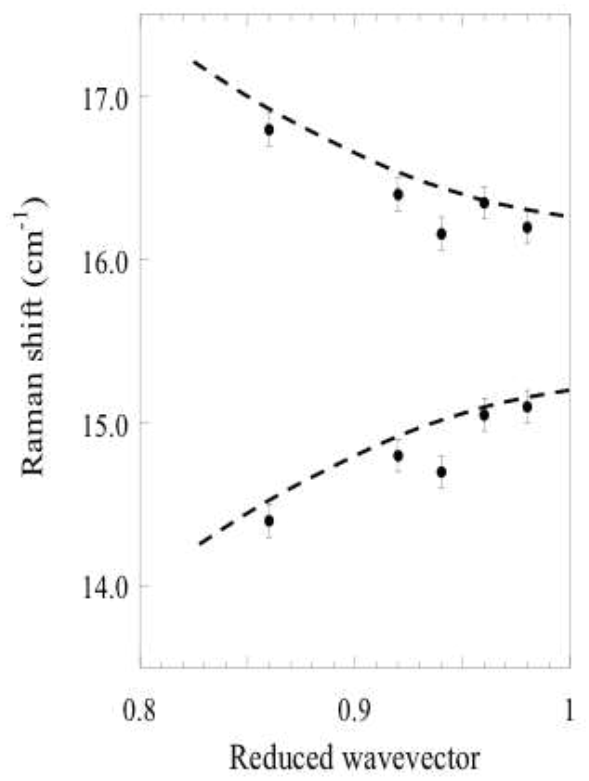

(b)

Figure 10. (a) Raman spectrum at low wavenumbers of a $\mathrm{Si} / \mathrm{Si}_{0.65} \mathrm{Ge}_{0.35}$ planar superlattice at room temperature. The acoustic phonon peaks visible in this spectrum appear in pairs in accordance with their zone folding index $\mathrm{m}$. The inset shows a schematic of the formation of the Brillouin mini-zone and the anticipated peak positions due to Raman interactions with folded longitudinal acoustic (FLA) phonons for this sample. (b) The measured points and dispersion relation (dashed lines) of the FLA phonons near the mini-zone-edge phononic band gap arising from the difference in the acoustic impedances of the two component layers of the $\mathrm{Si} / \mathrm{Si}_{0.5} \mathrm{Ge}_{0.5}$ superlattice. For further details, see Reference 19.

\section{Second-Order Raman Scattering in Si/SiGe Nanostructures}

In $\mathrm{Si} / \mathrm{SiGe}$ nanostructures, several Raman peaks associated with second-order light scattering are observed between 550 and $1100 \mathrm{~cm}^{-1}$ (Fig. 11). The two-transverse optical (2TO) Si phonon overtone features are related to scattering from the Brillouin zone critical points at $\mathrm{W}$ and $\mathrm{L}$, and occur at 940 and $975 \mathrm{~cm}^{-1}$, respectively $(26,27)$. The $2 \mathrm{TO}$ Raman signal shown in Fig. 11 is actually comprised of three peaks: the major Raman peak associated with scattering from the $2 \mathrm{TO}(\mathrm{L})$ phonon combination, the $2 \mathrm{TO}(\mathrm{W})$ Raman peak, and a weak shoulder associated with the $2 \mathrm{TO}(\Gamma)$ phonon overtone. In most of the $\mathrm{Si} / \mathrm{SiGe}$ nanostructures we investigated, we also found prominent Raman features associated with second order Si-Ge vibrations around $800 \mathrm{~cm}^{-1}$ and second order $\mathrm{Ge}-\mathrm{Ge}$ 
vibrations at $\sim 600 \mathrm{~cm}^{-1}$. Other weaker Raman features at $\sim 680 \mathrm{~cm}^{-1}$ and in the range of $840-900 \mathrm{~cm}^{-1}$ are, most likely, overtones of the first-order Ge-Ge (in the presence of $\mathrm{Si}$ ) and local Si-Si (in the presence of Ge) modes (27).

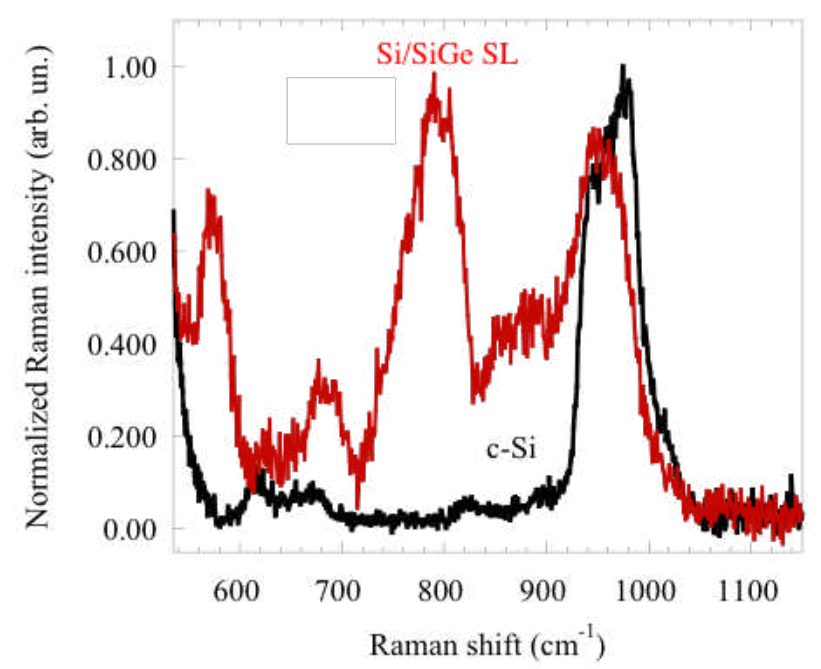

Figure 11. Spectral details of the second-order Raman scattering in c-Si and a $\mathrm{Si} / \mathrm{Si}_{1-\mathrm{x}} \mathrm{Ge}_{\mathrm{x}}$ superlattice $(\mathrm{SL})$ with $\mathrm{x}=0.4$ involving optical phonons at wavenumbers in the range $550-1150 \mathrm{~cm}^{-1}$.

\section{Strain and Chemical Composition in $\mathrm{Si} / \mathrm{Si}_{1-x} \mathrm{Ge}_{x}$ Nanostructures}

In $\mathrm{Si} / \mathrm{Si}_{1-\mathrm{x}} \mathrm{Ge}_{\mathrm{x}}$ nanostructures, correlations between the $\mathrm{Si}-\mathrm{Si}, \mathrm{Si}-\mathrm{Ge}$, and $\mathrm{Ge}-\mathrm{Ge}$ Raman peak wavenumbers, Ge content $x$, and strain $\varepsilon$ have been discussed extensively $(3,24,28)$. The relative numbers of chemical bonds comprising the $\mathrm{Si}-\mathrm{Si}, \mathrm{Si}-\mathrm{Ge}$, and $\mathrm{Ge}-$ Ge phonon modes are estimated to be varying with $\mathrm{x}$ as $(1-\mathrm{x})^{2}, 2 x(1-\mathrm{x})$, and $\mathrm{x}^{2}$, respectively. Since the Raman intensity is proportional to the scattering volume, the ratio of the integrated Raman peak intensities related to the relative number of chemical bonds of the corresponding phonon modes can be described as follows:

$$
I_{G e-G e} / I_{S i-G e}=B x / 2(1-x)
$$

and

$$
I_{S i-S i} I_{S i-\mathrm{Ge}}=A(1-x) / 2 x
$$

where coefficients $A$ and $B$ are related to the frequencies of the optical modes in the SiGe alloy. It was found experimentally that $B=3.2$ and $A=1.85$ for $457.9 \mathrm{~nm}$ excitation (29). This so-called intensity method for determining the value of $\mathrm{x}$ is independent of strain in the alloy layer and depends on the integrated intensity of the Raman signal associated with the phonon bands. In the Raman peak position (or wavenumber) method, a set of three equations is derived, where the peak positions of the three major vibrational modes in $\mathrm{Si} / \mathrm{Si}_{1-x} \mathrm{Ge}_{x}$ nanostructures are described as a function of $x$ and $\varepsilon$. The wavenumber of the phonon band can be expressed as: 


$$
\omega=\omega_{0}+b \varepsilon
$$

where $\omega_{0}$ is the $x$ dependent phonon frequency of the unstrained SiGe alloy and $b$ is the strain-shift coefficient. In the case of a strained $\mathrm{Si}_{1-x} \mathrm{Ge}_{x}(0<x<0.5)$ layer, the wavenumbers of the three different phonon modes are $(28,29)$ :

$$
\begin{aligned}
& \omega_{S i-S i}=520.2-70.5 x-830 \varepsilon, \\
& \omega_{S i-G e}=400.5+16.3 x-575 \varepsilon,
\end{aligned}
$$

and

$$
\omega_{G e-G e}=282.5+16 x-384 \varepsilon .
$$

The average values of $x$ and $\varepsilon$ in the alloy layer are

$$
x=\left[\left(\omega_{S i-G e}-400\right)-0.7\left(\omega_{S i-S i}-520\right)\right] / 65
$$

and

$$
\varepsilon=\left[\left(400-\omega_{S i-G e}\right)+0.23\left(520-\omega_{S i-S i}\right)\right] / 767 .
$$

On considering previously published data $(3,12,24)$, we find a reasonably good agreement between results obtained by both methods.

\section{Raman Studies of Thermal Conductivity and Heat Dissipation in $\mathbf{S i} / \mathbf{S i}_{1-\mathrm{x}} \mathbf{G e}_{\mathbf{x}}$ Nanostructures}

Typically, Raman scattering measurements are performed using an intense laser beam. While $\mathrm{c}-\mathrm{Si}$ and $\mathrm{c}-\mathrm{Ge}$ have a high thermal conductivity $\left(\kappa \approx 100 \mathrm{Wm}^{-1} \mathrm{~K}^{-1}\right)$, in compositionally disordered $\mathrm{SiGe}$ alloys and $\mathrm{Si} / \mathrm{SiGe}$ nanostructures $\kappa \leq 10 \mathrm{~W} \mathrm{~m}^{-1} \mathrm{~K}^{-1}(30)$. Thus, a significant temperature increase of a sample might occur during Raman scattering measurements and it will affect the Raman peak position, width, and line shape. Using a model based on the Fourier law of heat conduction, the thermal conductivity can be calculated as

$$
\kappa=P^{*}(L / A)^{*}(1 / \Delta T),
$$

where $P$ is the laser power absorbed by a sample with a thickness $L$ in the direction normal to a surface of a cross-sectional area $A$ due to a temperature gradient $\Delta T$. The temperature gradient is established between the highest temperature at the sample surface and the lowest temperature of the c-Si substrate (due to the high c-Si thermal conductivity), and these temperatures can be calculated using the Stokes/anti-Stokes Raman peak intensity ratio $\mathrm{I}_{\mathrm{S}} / \mathrm{I}_{\mathrm{aS}}$ for strained $\mathrm{Si}$ and $\mathrm{Si}-\mathrm{Ge}$ phonon modes and the $\mathrm{Si}-\mathrm{Si}$ mode at $520 \mathrm{~cm}^{-1}$ (assuming that it is associated with the c-Si substrate). This is because, to a good approximation, $I_{S} / I_{a S}=\exp \left(\hbar \omega / k_{B} T\right)$, where $\hbar=h / 2 \pi$, h is Planck's constant, $k_{B}$ is Boltzmann's constant, and $\mathrm{T}$ is the sample temperature, provided that the excitation conditions are the same for both the Stokes and anti-Stokes scattering and there is no Ge 
resonance effect (see the Introduction). In measured samples (see, for example, Fig. 12) the calculated thermal conductivity is $\sim 12 \mathrm{~W} \mathrm{~cm}^{-1} \mathrm{~K}^{-1}$ for $\mathrm{Si} / \mathrm{Si} / \mathrm{SiGe} \mathrm{SLs}$ and is $\sim 4 \mathrm{~W}$ $\mathrm{cm}^{-1} \mathrm{~K}^{-1}$ in $\mathrm{Si} / \mathrm{SiGe} \mathrm{CMs}$, respectively. The reason for the lower thermal conductivity found in $\mathrm{Si} / \mathrm{SiGe} \mathrm{CMs}$ compared to $\mathrm{Si} / \mathrm{SiGe} \mathrm{SLs}$ can be explained by analyzing a comparative volume fraction of $\mathrm{SiGe}$ (a lower thermal conductivity material) versus c-Si (a higher thermal conductivity material) and quality of the $\mathrm{Si} / \mathrm{SiGe}$ heterointerfaces. In $\mathrm{Si} / \mathrm{SiGe} \mathrm{CMs}$, we typically find that the volume fraction of SiGe is nearly twice that of $\mathrm{Si} / \mathrm{SiGe} \mathrm{SLs}$, and it has been noted that inelastic scattering of phonons in $\mathrm{Si} / \mathrm{SiGe}$ nanostructures with a diffuse interface also contributes to the reduction in the thermal conductivity (31). It was also reported that the temperature calculated according to Boltzmann statistics under a non-resonant excitation condition of the Ge-Ge phonon mode is consistently lower than that found for the Si-Ge and Si-Si modes (30). This discrepancy can be explained assuming that at the laser excitation wavelengths used, the Ge-Ge phonon mode has a resonant component, as pointed out in References 12, 32, and 33.

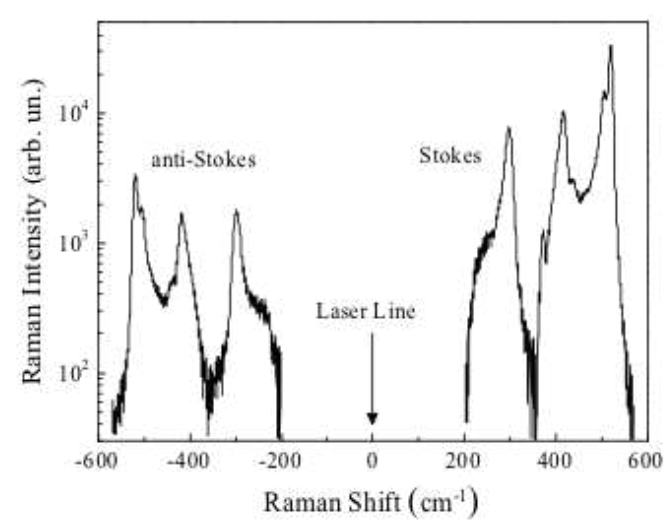

(a)

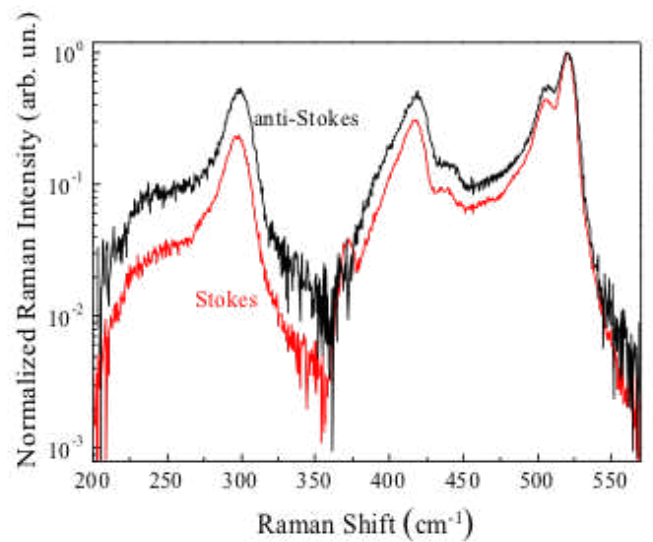

(b)

Figure 12. A comparison of the Stokes and anti-Stokes Raman spectrum recorded nominally at room temperature for a $\mathrm{Si} / \mathrm{SiGe}$ cluster multilayer nanostructure sample. (a) The raw spectrum. (b) The Stokes and anti-Stokes spectra scaled to show the differences in the relative intensities of the main features.

\section{Polarization Dependent Raman Scattering in Si/SiGe Nanostructures}

Polarized Raman scattering in the form of polar plots provides information on the Raman scattering intensity as a function of the polarization angle of the scattered light (16-18). The particular shape of the polar plot depends on the symmetry of the vibrational mode being measured and the crystallographic orientation of the sample. Figure 13 displays angular Raman polarization diagrams for three different vibrational modes ( $\mathrm{Si}-\mathrm{Si}$ at $520 \mathrm{~cm}^{-1}, \mathrm{Si}-\mathrm{Ge}$ at $415 \mathrm{~cm}^{-1}$, and $\mathrm{Ge}-\mathrm{Ge}$ at $298 \mathrm{~cm}^{-1}$ ) for a $\mathrm{Si} / \mathrm{SiGe} \mathrm{S-K}$ $\mathrm{CM}$ sample (16). The observed angular dependencies of the $\mathrm{Ge}-\mathrm{Ge}$ and $\mathrm{Si}-\mathrm{Ge} \mathrm{Raman}$ mode intensities are nearly identical to that measured in a (100)-oriented Si single crystal (shown in Fig. 13 by the solid line). However, a quite different behavior is observed in the Raman polarization dependence for the Si-Si Raman mode at $520 \mathrm{~cm}^{-1}$. The observed deviation is explained by strain-induced partial relaxation of selection rules, mixing of different phonon modes in the nanometer-thick Si layers separating the SiGe cluster layers, and, possibly, from scattering in a thin layer of the c-Si substrate directly under the sample, which can exhibit stress in response to the S-K CM structure above it. The 
strong localization of strain observed in the $\mathrm{Si}$ layers is consistent with present understanding of the nature of vertical self-ordering produced by strain propagation in $\mathrm{Si} / \mathrm{SiGe} \mathrm{S}-\mathrm{K} \mathrm{CM}$ nanostructures. Similar measurements performed on $\mathrm{Si} / \mathrm{SiGe} \mathrm{SL}$ samples did not reveal any deviation from the data obtained in (100) c-Si substrates.

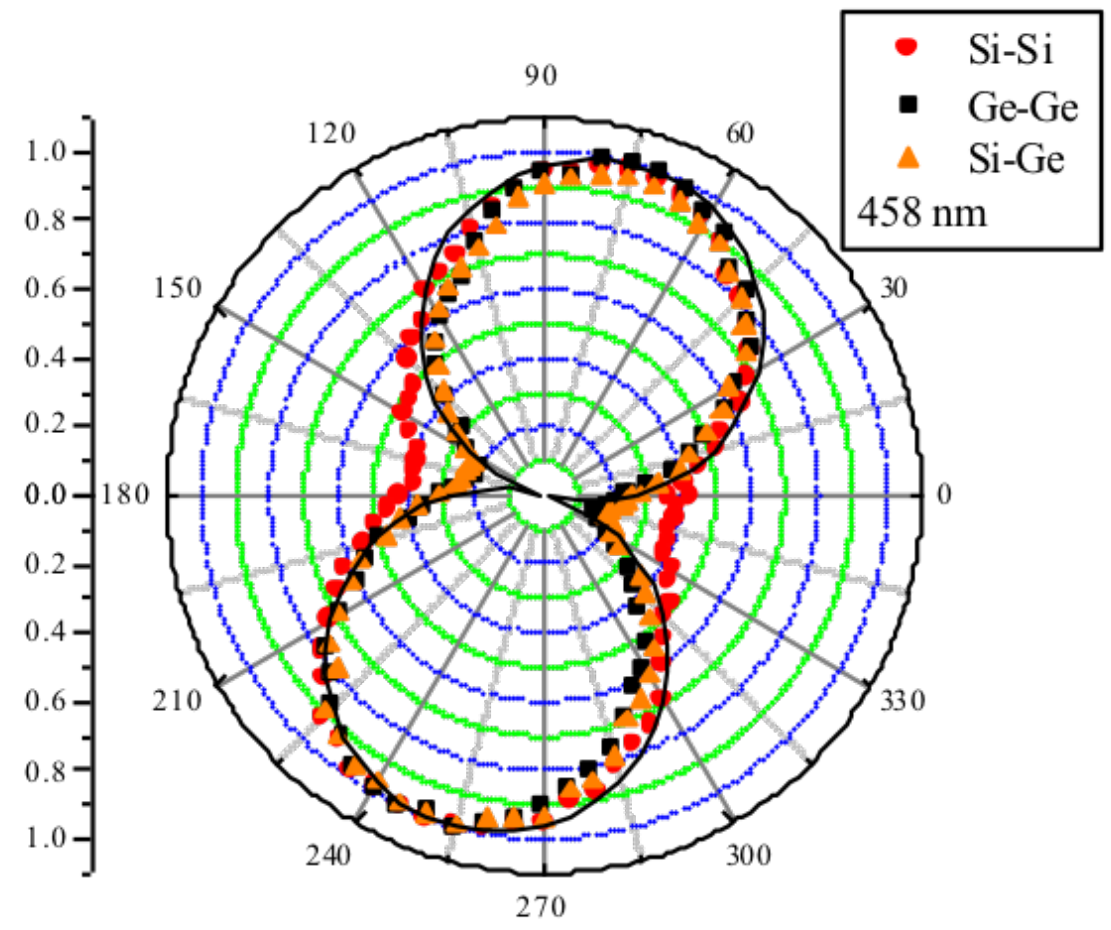

Figure 13. Angular Raman polarization diagrams of the $\mathrm{Si}-\mathrm{Si}, \mathrm{Si}-\mathrm{Ge}$, and $\mathrm{Ge}-\mathrm{Ge}$ vibrational modes for a $\mathrm{Si} / \mathrm{SiGe}$ Stranski-Krastanov cluster multilayer sample measured at room temperature using laser excitation at $457.9 \mathrm{~nm}$. The Raman polarization diagram of single-crystal (100)Si (solid line) is shown for comparison.

\section{Conclusions}

In conclusion, this review of the various phenomena associated with first- and second-order inelastic light scattering in $\mathrm{Si} / \mathrm{SiGe} \mathrm{SLs}$ and $\mathrm{S}-\mathrm{K} \mathrm{CM}$ s provides an analysis of the Raman spectrum dependence on strain and chemical composition, discusses lowwavenumber Raman scattering associated with folded acoustic phonon modes in periodic $\mathrm{Si} / \mathrm{SiGe}$ nanostructures, and analyzes a laser-induced sample temperature increase during Raman scattering measurements. The results presented here are important for the development of practical quantitative and non-destructive metrological procedures for a wide variety of SiGe based nanoscale electronic, photonic, and thermoelectric devices. In this overview, we do not discuss several other particular analytical techniques such as surface- and tip-enhanced Raman scattering (34) and non-linear Raman scattering $(35,36)$. We think that these important phenomena require their own in-depth consideration and should be covered in a separate review. 


\section{Acknowledgments}

We thank our many co-workers and colleagues who have contributed over the last three decades to the Raman studies of SiGe nanostructures, and in particular H.J. Labbé, S. Moisa, and J.P. McCaffrey of the National Research Council, and H.K. Shin. L. Tsybeskov would like to acknowledge support by the Foundation at NJIT, Intel, HewlettPackard Laboratories and NSF Award 1027770.

\section{References}

1. M. Cardona and G. Güntherodt, Editors, Light Scattering in Solids V, Springer, Berlin (1989).

2. A. Guinier, X-Ray Diffraction, Freeman, San Francisco (1963).

3. D. J. Lockwood and J.-M. Baribeau, "Characterization of Strain and Epitaxial Quality in Si/Ge Heterostructures," in Light Scattering from Semiconductor Structures and Superlattices, D. J. Lockwood and J. F. Young, Editors, p. 197, Plenum, New York (1991).

4. F. Cerdeira, A. Pinczuk, J. C. Bean, B. Batlogg, and B. A. Wilson, Appl. Phys. Lett. 45, 1138 (1984).

5. J. L. Liu, Y. S. Tang, K. L. Wang, T. Radetic, and R. Gronsky, Appl. Phys. Lett. 74, 1863 (1999).

6. E. G. Barbagiovanni, D. J. Lockwood, P. J. Simpson, and L. V. Goncharova, J. Appl. Phys. 111, 034307 (2012).

7. J. Menéndez, A. Pinczuk, J. Bevk, and J. P. Mannaerts, J. Vac. Sc. Techn. B 6, 1306 (1988).

8. B. V. Kamenev, L. Tsybeskov, J.-M. Baribeau, and D. J. Lockwood, Appl. Phys. Lett. 84, 1293 (2004).

9. M. Cardona and P. Yu, Fundamentals of Semiconductors, p. 619, Springer-Verlag, Berlin (2005).

10. M. I. Alonso and K. Winer, Phys. Rev. B 39, 10056 (1989).

11. P. M. Mooney, F. H. Dacol, J. C. Tsang, and J. O. Chu, Appl. Phys. Lett. 62, 2069 (1993).

12. S. A. Mala, L. Tsybeskov, D. J. Lockwood, X. Wu, X., and J.-M. Baribeau, J. Appl. Phys. 116, 014305 (2014).

13. W. Hayes and R. Loudon, Scattering of Light by Crystals, Wiley, New York (1978).

14. F. Cerdeira, M. I. Alonso, D. Niles, M. Garriga, M. Cardona, E. Kasper, and H. Kibbel, Phys. Rev. B 40, 1361 (1989).

15. M. Cazayous, J. R. Huntzinger, J. Groenen, A. Mlayah, S. Christiansen, H. P. Strunk, O. G. Schmidt, and K. Eberl, Phys. Rev. B 62, 7243 (2000).

16. B. V. Kamenev, H. Grebel, L. Tsybeskov, T. I. Kamins, R. S. Williams, J.-M. Baribeau, and D. J. L. Lockwood. Appl. Phys. Lett. 83, 5035 (2003).

17. M. Mermoux, A. Crisci, F. Baillet, V. Destefanis, D. Rouchon, A. M. Papon, and J. M. Hartmann, J. Appl. Phys. 107, 013512 (2010).

18. A. V. Baranov, A. V. Fedorov, T. S. Perova, R. A. Moore, V. Yam, D. Bouchier, V. Le Thanh, and K. Berwick, Phys. Rev. B 73, 075322 (2006).

19. P. X. Zhang, D. J. Lockwood, H. J. Labbé, and J.-M. Baribeau. Phys. Rev. B 46, 9881 (1992).

20. D. J. Eaglesham and M. Cerullo, Phys. Rev. Lett. 64, 1943 (1990). 
21. F. M. Ross, J. Tersoff, and R. M. Tromp. Phys. Rev. Lett. 80, 984 (1998).

22. J. A. Floro, E. Chason, L. B. Freund, R. D. Twesten, R. Q. Hwang, and G. A. Lucadamo. Phys. Rev. B 59, 1990 (1999).

23. J.-M. Baribeau, X. Wu, N. L. Rowell, and D. J. Lockwood, J. Phys.: Condens. Matter, 18, R139 (2006).

24. H. K. Shin, D. J. Lockwood, and J.-M. Baribeau, Solid State Commun., 114, 505 (2000).

25. S. M. Rytov, Sov. Phys. Acoust. 2, 68 (1956).

26. P. A. Temple and C. E. Hathaway, Phys. Rev. B 7, 3685 (1973).

27. J. S. Lannin, Phys. Rev. B 16, 1510 (1977).

28. T. S. Perova, J. Wasyluk, K. Lyutovich, E. Kasper, M. Oehme, K. Rode, and A. Waldron, J. Appl. Phys. 109, 033502 (2011).

29. P. M. Mooney, F. H. Dacol, J. C. Tsang, and J. O. Chu, Appl. Phys. Lett. 62, 2069 (1993).

30. H.-Y. Chang and L. Tsybeskov, in Silicon Nanocrystals: Fundamentals Synthesis and Applications, L. Pavesi and R. Turan, Editors, p. 105, Wiley-VCH, Weinheim (2010).

31. G. Chen, Phys. Rev. B 57, 14958 (1998).

32. K. Brunner, Reports on Progress in Physics 65, 27 (2001).

33. R. Schorer, G. Abstreiter, H. Kibbel, H. Presting, C. Tserbak, and G. Theodorou, Solid State Commun. 93, 1025 (1995).

34. Y. Saito, M. Motohashi, N. Hayazawa, M. Iyoki, and S. Kawata, Appl. Phys. Lett. 88, 143109 (2006).

35. R. Claps, V. Raghunathan, D. Dimitropoulos, and B. Jalali, Opt. Expr. 12, 2774 (2004).

36. H. Rong, A. Liu, R. Jones, O. Cohen, D. Hak, R. Nicolaescu, A. Fang, and M. Paniccia, Nature 433, 292 (2005). 